\title{
ENSAIO COMO ESCRITA ACADÊMICA E A PRODUÇÃO DE PROJETOS E PESQUISAS
}

\author{
Essay as academic writing and the production of projects \\ and research
}

\section{El ensayo como escritura académica y la producción de proyectos e investigaciones}

\section{Carin Cristina Dahmer ${ }^{\alpha}$, Angélica Neuscharank ${ }^{\beta}$ e Marilda Oliveira de Oliveirar}

Data de recepção: 28/12/2018 • Data de aceitação: 16/05/2019

Resumo. Este artigo propõe pensar a escrita acadêmica a partir de experiências com orientações de pesquisas em um curso de formação de professores/as em artes visuais, do estado do Rio Grande do Sul, no Brasil. Deste modo, busca-se compartilhar algumas inquietações produzidas em meio aos processos de escrita de projetos de ensino e pesquisa e trabalhos finais de graduação. Escolheu-se para compor as questões teóricas o entrecruzamento de alguns estudos a partir do que propõe Pereira sobre os usos das palavras, enquanto uma arena política, uma arma e um efeito de negociação; os apavoramentos produzidos diante de uma forma hegemônica de escrever na academia, pontuados por Silva; a proposta do ensaio como escrita e a experiência junto de Larrosa, bem como a noção de texto-leitura apontada por Barthes que se pauta no que o leitor produz de sentidos ao ler um texto. Como método, pensou-se em possíveis experimentações de uma escrita-ensaio, que perpassam modos outros de escrever, apostando na literatura e na arte como variações para

\footnotetext{
a Programa de Pós-Graduação em Educação. Centro de Educação. Universidade Federal de Santa Maria, Av. Roraima, 1000, CP 5082. Cidade Universitária. Santa Maria. Rio Grande do Sul. Brasil. carindahmer@gmail.com

${ }^{\text {B }}$ Programa de Pós-Graduação em Educação. Centro de Educação. Universidade Federal de Santa Maria, Av. Roraima, 1000, CP 5082. Cidade Universitária. Santa Maria. Rio Grande do Sul. angelicaneuscharank@yahoo.com.br

$\gamma$ Departamento de Metodologia do Ensino. Programa de Pós-Graduação em Educação. Centro de Educação. Universidade Federal de Santa Maria, Av. Roraima, 1000, CP 5082. Cidade Universitária. Santa Maria. Rio Grande do Sul. oliveira.marilda27@gmail.com
}

Como citar este artigo: Dahmer, Carin Cristina, Angélica Neuscharank e Marilda Oliveira de Oliveira. «Ensaio como escrita acadêmica e a produção de projetos e pesquisas». Historia y Memoria de la Educación 11 (2020): 475-499 
a escrita acadêmica. Nesse sentido, concluímos que o contributo de uma pesquisa no campo da educação das artes visuais não necessita propor uma transformação nos espaços da pesquisa, ou nos colaboradores, mas que ela possa produzir efeitos no pesquisador/pesquisadora, ao produzir sentidos para ele/ela. Propomos que os espaços acadêmicos possam acolher outras formas de escrita que se organizem de modos diferentes, seja em relação ao seu formato ou quanto ao uso das imagens como tensionadoras do texto, produzindo conhecimento e problematizando o campo da pesquisa e da educação.

Palavras-chave: Escrita acadêmica; Ensaio; Leitura; Ensino; Pesquisa.

Abstract. This article proposes to think of academic writing from experiences with research orientations in a teacher training course in visual arts, from the state of Rio Grande do Sul, Brazil. In this way, it is sought to share some concerns produced in the middle of the writing processes of teaching and research projects and final graduate work. It was chosen to compose the theoretical questions the interweaving of some studies from what Pereira proposes about the uses of words, as a political arena, a weapon and a negotiating effect; the terrors of a hegemonic form of writing in the academy, punctuated by Silva; the proposal of the essay as written and the experience with Larrosa, as well as the notion of text-reading pointed out by Barthes that is based on what the reader produces of senses when reading a text. As a method, it was thought possible experiments of a writing-essay, that perpass other ways of writing, betting on literature and the art like variations for the academic writing. In this sense, we conclude that the contribution of a research in the field of visual arts education does not need to propose a transformation in the research spaces, or in the collaborators, but that it can produce effects in the researcher, when producing senses for him/her. We propose that academic spaces can accommodate other forms of writing that are organized in different ways, be it in relation to its format or the use of images as text tensors, producing knowledge and problematizing the field of research and education.

Keywords: Academic writing; Reading; Essay; Teaching; Research.

Resumen. Este artículo propone pensar la escritura académica a partir de experiencias con tutorías de investigación en un curso de formación de profesorado en artes visuales, de la provincia Río Grande do Sul, en Brasil. De este modo, se busca compartir algunas inquietudes producidas en medio a los procesos de escritura de proyectos de enseñanza e investigación y trabajos de conclusión de curso. Se eligió para componer las cuestiones teóricas el entrecruzamiento de algunos estudios a partir de lo que propone Pereira sobre los usos de las palabras, mientras una arena politica, una arma y un efecto de negociación; los terrores producidos delante una forma hegemónica 
de escribir en el mundo académico, señalados por Silva; la propuesta del ensayo como escritura y la experiencia junto a Larrosa, así como la noción de texto-lectura apuntada por Barthes que se basa en lo que el lector produce de sentidos al leer un texto. Como método, se pensó en posibles experimentaciones de una escritura-ensayo, que atraviesan otros modos de escribir, apostando en la literatura y en el arte como variaciones para la escritura académica. En este sentido, concluimos que la contribución de una investigación en el campo de la educación de las artes visuales no necesita proponer una transformación en los espacios de investigación, o en los colaboradores, sino que ella pueda producir efectos en el investigador/investigadora al producir sentidos para él/ella. Proponemos que los espacios académicos puedan acoger otras formas de escritura que se organicen de diferentes modos, sea en relación a su formato o cuanto al uso de las imágenes como tensoras del texto, produciendo conocimiento y problematizando el campo de la investigación y de la educación.

Palabras clave: Escritura académica; Ensayo; Lectura; Enseñanza; Investigación.

\section{INTRODUÇÃO}

Intenta-se neste artigo problematizar a escrita acadêmica e pensar sobre certos modos de escrita que adentram o campo da produção do conhecimento, nos meios acadêmicos e científicos, propondo o ensaio como potente possibilidade para tal. Compreendemos que o processo de escrita perpassa uma série de saberes e fazeres institucionais e, como compartilha Jorge Larrosa ${ }^{1}$ em uma conversa com Basil Bernstein sobre a compreensão da estrutura de uma prática institucional: é preciso saber o que ela proíbe para conhecê-la, o que implica repensarmos a produção da escrita acadêmica, conhecermos os discursos em torno dos possíveis limites e regras estabelecidas para o seu funcionamento.

Larrosa $^{2}$ sinaliza que os dispositivos controladores de certos saberes perpassam também o controle da linguagem e de como nos relacionamos com ela, nossas práticas de ler, escrever, falar e escutar. «Nosso trabalho na academia tem a ver com o saber, é basicamente um trabalho

\footnotetext{
1 Jorge Larrosa, "O ensaio e a escrita acadêmica", en Uma escrita acadêmica outra: ensaios, experiências e invenções, orgs. Cristiana Callai e Anelice Ribetto (Rio de Janeiro: Lamparina, 2016), 17-30.

2 Larrosa, «O ensaio e a escrita acadêmica», 17.
} 
com palavras. O que fazemos a cada dia é escrever e ler, falar e escutar». ${ }^{3}$ Todo modo de pensar, implica um modo de nos relacionarmos com a linguagem, diz de nossos processos de ler e escrever.

Assim, escrever é um processo que está diretamente vinculado à leitura, que, por sua vez, implica nos aproximarmos de muitos e diversos referenciais, para que as palavras devoradas possam gerar escritas. Demanda tempo, dedicação e envolvimento. Entretanto, escrever no contexto acadêmico não tem sido vinculado apenas às leituras em demasia e ao prazer de trabalhar com as palavras; muito antes, é apresentado como um exercício obrigatório, cuja principal demanda está muitas vezes relacionada ao cumprimento de regras e ao enquadramento às normas que regem esse exercício. Ao considerarmos, por exemplo, que o principal objetivo da produção de um trabalho de conclusão de curso está nessa aproximação do/a acadêmico/a em adquirir uma «noção» do que é produzir pesquisa.

Pensamos, dessa forma, na urgência em falar sobre a escrita produzida no meio acadêmico, mais especificamente a partir de um curso de formação de professores/as em artes visuais, no qual estamos inseridas como docentes. Observamos um número expressivo de casos de estudantes que apresentam certo «bloqueio», "paralisia», no momento da escrita, seja de um projeto de ensino e pesquisa ${ }^{4}$ (projeto preparatório para realização do Estágio Curricular Supervisionado), ou de um trabalho de conclusão de curso, ${ }^{5}$ no qual as dificuldades em lidar com

\footnotetext{
3 Larrosa, "O ensaio e a escrita acadêmica», 17.

${ }^{4}$ Os projetos de ensino e pesquisa são desenvolvidos na disciplina Prática Educacional IV do curso de graduação em artes visuais licenciatura. Eles têm como objetivo discutir a educação das artes visuais vinculada a pesquisa, delineando de forma inicial o campo do Estágio Curricular Supervisionado, visando a discussão sobre a atuação profissional do professor-pesquisador no campo da educação das artes visuais e as alianças entre universidade e escola. Os projetos são produzidos individualmente pelos estudantes, articulando o ensino e a pesquisa, de forma a contemplar as abordagens atuais para a educação das artes visuais e que tenha como objetivo ser posto em prática nos semestres subsequentes durante os estágios curriculares supervisionados I, II, III e IV. Esse processo visa as relações entre a arte e a educação, pelo viés não apenas da execução de um plano de aula ou de procedimentos metodológicos, mas perpassa a pesquisa como o elemento que irá acompanhar, movimentar, dar fôlego ao projeto e as aulas de arte, como um convite para relacionarmos a arte, a educação e a pesquisa por um viés colaborativo e investigativo para a produção de projetos de ensino e pesquisa.

${ }_{5}^{5}$ Os trabalhos de conclusão de curso (TCCs) são, eventualmente, escritos no final do curso de graduação em artes visuais licenciatura. Os/as acadêmicos/acadêmicas escolhem quem irá orientá-los/orientá-las de acordo com a área e temática escolhida. A realização da pesquisa acontece,
} 
situações que solicitem a produção de uma escrita aparecem. Vinculamos muitos desses entraves às exigências e aos modelos de escrita que circulam nesses espaços, além das regras gramaticais, formatação do texto, embasamento teórico, e demais demandas de uma escrita que «dê conta» de racionalizar as experiências, apresentar resultados, explicitar os dados aos leitores e comunicar algo.

Dessa forma, intentamos compartilhar algumas inquietações que nos tem movimentado a pensar nos processos de pesquisa e escrita, considerando nossa atuação em orientações de produções escritas no contexto acadêmico. Além dessa partilha, pretendemos apresentar algumas leituras que viemos realizando sobre uma escrita que possa fazer vazar os modelos acadêmicos, apostando, assim, na arte e na literatura como aliados que possam propor outros modos de escrever nesse espaço da graduação.

Assim, iniciaremos pontuando algumas situações observadas sobre a escrita acadêmica, comentando sobre as exigências, normatizações e os excessos que foram percebidos. Logo, abordaremos as relações de pesquisa e escrita na elaboração de projetos de ensino e pesquisa e trabalhos de conclusão de curso, de modo a compartilhar o que experienciamos dessa produção, conversando ao longo do texto com autores como Roland Barthes, Jorge Larrosa, Marcos Villela e Anelice Ribetto, para propormos experimentações de criação com a escrita, muito além de procedimentos. Para que possamos contribuir, assim, na pesquisa dos acadêmicos e, quiçá, tornarmos o olhar para estes processos mais leves e saborosos.

\section{POR QUE A ESCRITA ACADÊMICA PROVOCA APAVORAMENTOS? POR ONDE COMEÇAR A ESCREVER?}

Iniciamos nossa proposta a partir do meio, problematizando o que se passa «entre» as linhas que compõem uma escrita: as palavras e suas

geralmente, em um semestre, onde muitos dão continuidade aos projetos de ensino e pesquisa produzidos no decorrer do curso. A ênfase está na aproximação com a produção acadêmica e com a pesquisa de temáticas emergentes para o ensino das artes visuais na contemporaneidade. Dessa forma, muitos são capturados/capturadas por temáticas que desenvolvem nos estágios junto às escolas. A escrita varia de cinquenta à oitenta páginas, considerando que realizam a defesa do trabalho final à uma banca composta por dois docentes avaliadores, mais o/a orientador/orientadora. 
relações com a pesquisa. Independentemente se «falamos de ciência, de conversa, de poesia ou de literatura: a palavra é, ao mesmo tempo, uma arena política, uma arma e um efeito da negociação» ${ }^{6}$ ela implica a coexistência de dois ou mais posicionamentos. Primeiro porque ela aprisiona o pensamento, é uma parada em relação ao movimento infinito e intensivo que é o fluxo da consciência, ela demarca, dá forma ao pensamento, põe limite ao exercício de ensaio e criação. No entanto, «nenhuma palavra é bastante para dizer tudo aquilo, (na extensão e na intensidade) que ela pretende dizer». ${ }^{7}$ Segundo, porque ela dá vida, cria, dá corpo aos conceitos, às sensações, noções e invenções. As palavras são resíduos de verdades, são fixações de tempos e existências.

Assim, há um infinito conjunto de possibilidades quando pensamos nas palavras, e, por isso mesmo, impossível de ser contido em apenas um modo de arranjá-las, um postulado universal, mais ou menos legítimo. Trataremos de olhar para a escrita como uma forma de negociação: de significados, de sentidos, de verdades.

A escrita acadêmica que estamos a pensar, mais especificamente a escrita de projetos de ensino e pesquisa, e trabalhos de conclusão de curso, é uma escrita "propositalmente arranjada para produzir efeitos de verdades, isso porque ela é verdadeira enquanto enunciado, enquanto significante de algo». ${ }^{8}$ Portanto, nos propomos a olhar para as demandas que a vida acadêmica impõe sobre os sujeitos que a constituem e a vivem, mais especificamente sobre os estudantes do curso de licenciatura em artes visuais, a partir do que consideramos ser potente pensar sobre as palavras.

Uma das mais recorrentes dificuldades dos acadêmicos tem sido o iniciar de uma escrita, pensar nas palavras, ideias, autores e acontecimentos que vão compor esse processo. Para não desviarmos do termo utilizado neste artigo, a solicitação de uma escrita tem causado «apavoramento» aos licenciandos em artes visuais, certo receio de escrever. A «síndrome da folha em branco» foi tema de escrita de alguns autores

\footnotetext{
"Marcos Villela Pereira, "A escrita acadêmica: do excessivo ao razoável», Revista Brasileira de Educação 18, no. 52 (2013): 2.

7 Pereira, "A escrita acadêmica», 1.

8 Pereira, "A escrita acadêmica», 2.
} 
que trabalham com a linguagem, como Tomaz Tadeu da Silva ${ }^{9}$, que nos ajudam a pensar que o temor de estar em frente a uma folha ou tela em branco, é um fenômeno recorrente para quem escreve.

Sobre esse assunto, Silva ${ }^{10}$ aponta algumas sugestões para lidar com esses «bloqueios» e que abordaremos junto das experiências que aqui serão compartilhadas. O fato é que o processo de escrita não apresenta «receitas», procedimentos e métodos a priori, mas diz respeito a um modo de pesquisar singular, portanto, não há como afirmar que tenhamos uma única via de iniciar uma escrita e de desenvolver uma pesquisa. O que temos presenciado é certa ansiedade dos acadêmicos por ouvir do orientador por "onde» iniciar a pesquisar, como se houvesse um início, meio e fim, caminhos estabelecidos e delimitados.

Silva comenta que os dois passos iniciais seriam assegurar que temos algo a dizer e fazer um plano geral sobre o que pretendemos escrever. Com base nisso, acrescentaríamos que um modo prazeroso de iniciar é organizando as ideias que já são conhecidas sobre o tema que será pesquisado. Isso implica fazer um mapa conceitual, esquemas, esboços e anotações sobre o que nos inquieta, afeta e movimenta da temática, isto é, iniciar por nossas experiências de modo a escrever sem compromissos teóricos, nesse primeiro momento, estabelecendo quais serão os temas gerais e secundários.

Ainda sobre iniciar a escrita, o autor nos fala que tentar seguir uma "ordem», como iniciar pela introdução, justificativa, ou até mesmo um capítulo e querer concluí-lo antes de seguir para outra etapa, é um modo arriscado e que abre margem para sofrermos da síndrome da folha em branco, isto é, ficarmos suscetíveis a possíveis «bloqueios». No entanto, iniciar por outros caminhos nem sempre é um movimento fácil, visto que, nosso pensamento funciona de forma ordenada, cartesiana e linear.

Assim, ao longo das orientações dos projetos de ensino e pesquisa e dos trabalhos de conclusão de curso, temos pensado e orientado que a escrita inicie por vias de interesse do pesquisador/pesquisadora, por

\footnotetext{
9 Tomaz Tadeu da Silva, Como enfrentar a síndrome da folha em branco. Argumentação, estilo, composição: Introdução a escrita acadêmica. Programa de Pós-Graduação em Educação, Universidade Federal do Rio Grande do Sul. S/d.

${ }^{10}$ Silva, Como enfrentar a sindrome da folha em branco, 1.
} 
caminhos que estejam latentes, que tragam fôlego para a pesquisa, que possam se desdobrar em diálogos com os autores e com os dados levantados/produzidos. As nossas alianças têm gerado muitos frutos, porque não temos imposto a necessidade de uma estrutura universal, mas que cada pesquisador/pesquisadora encontre caminhos para iniciar e organizar sua pesquisa, seu projeto. Não abandonamos passos fundamentais, como: delimitação do tema (propósito e foco), o problema de pesquisa e objetivos, escolha dos autores, recolha/produção dos dados, apresentação de uma metodologia, e retomada de todos esses processos através das considerações finais, mas problematizamos como os mesmos se dão, como uma proposta de pensar esses meios de modo singular.

Temos também trabalhado as relações de tempos nas pesquisas, pois estabelecer metas, datas e prazos tem sido um movimento importante, ao passo que temos aprendido a nos relacionarmos com o tempo de escrita de cada um. Orientamos também que não há um tempo ideal, ordenado, mínimo ou máximo, não há momento certo para escrever, mas a escrita não pode esperar: não espera uma frase perfeita, ideias extraordinárias, uma sequência lógica, pois a escrita é acontecimento, ${ }^{11}$ portanto, a potência está em escrever no momento em que temos uma ideia, ainda que em pedaços, por fragmentos, sem a preocupação de como estas se encaixarão posteriormente.

Portanto, nos aproximamos do que Larrosa ${ }^{12}$ aponta como um ensaio, como possibilidade de escrita, pois ele aceita e assume o caráter temporário e efêmero do tempo, sua própria finitude. O ensaísta não escreve para a eternidade, mas de forma atemporal, não escreve para todos e para ninguém, mas para um determinado tempo e contexto.

Considerando o caráter efêmero e singular da escrita-ensaio, existem várias formas de organizarmos nossas ideias, através de mapas, gráficos, diagramas, desenhos, entre outros exemplos, que auxiliam a escrita a

\footnotetext{
${ }_{11}$ Acontecimento - Na proposição deleuzeana, o acontecimento não é subjetivo nem objetivo, não está vinculado ao temporal nem intemporal, tampouco histórico e eterno, não pertence ao presente, passado ou futuro, nem a divisão entre abstrato e concreto. $\mathrm{O}$ acontecimento é o que acaba de acontecer e o que ainda vai acontecer, mas nunca o que se passa, pois não chega a se efetuar. É como um "entre-tempo", que "marca uma cesura, um corte, de modo que o tempo se interrompe para retomar sobre outro plano» François Zourabichvili, O vocabulário de Deleuze (Rio de Janeiro: Sinergia - Relume Dumará, 2004), 12-13).
}

12 Larrosa, "O ensaio e a escrita acadêmica», 25. 
manter um fio condutor diante dos interesses de pesquisa. Sob essa questão, observamos ser importante pensar que:

Durante o período de envolvimento em um projeto de escrita, esteja sempre à espreita de ideias. É claro que os locais e os objetos em que você poderá achar inspiração variam de acordo com o tipo de tema e objetivo de seu texto, mas, em qualquer caso, é sempre possível esperar encontrar ideias nos mais variados tipos de fontes. Além disso, estar permanentemente à espreita mantém a sua mente funcionando em função da escrita de seu texto mesmo quando você não está especificamente envolvido em escrevê-lo. Assim, por exemplo, ao ver um filme ou uma exposição de arte ou mesmo ao ler um livro não diretamente relacionado à sua escrita naquele momento particular, faça sua mente interagir com esse material em função do tema do texto que você está escrevendo. Não deixe, entretanto, de anotar as ideias que lhe surgirem. ${ }^{13}$

Pelos diferentes elementos, força as e disparadores que atravessam os corpos dos pesquisadores/pesquisadoras, é que Silva ${ }^{14}$ comenta que é preciso estar à espreita do que vivemos, pois isso também produzirá efeitos sobre nossa escrita, sobre nosso pensamento. Trata-se de acolher o inesperado como potência que nos movimenta a conectar as ideias e as temáticas para lugares que não haviam sido pensados até então, e, talvez esteja aí um dos principais objetivos de escrever e pesquisar na academia: o alargamento e extensão dos nossos saberes; o não controle dos rumos da pesquisa; um problema de pesquisa elaborado sem uma resposta a priori.

Diante dessas questões apresentadas, por que a escrita acadêmica provoca apavoramentos? Escrevemos para quem? Que escrita nos é solicitada e o que compreendemos da mesma? A forma hegemônica de escrita acadêmica acabou aderindo aos preceitos da ciência e de um modelo de escrita científica, como mencionamos no início do artigo, há uma performance discursiva que constitui campos de validade e que busca «dar corpo à interpretação objetiva da realidade, superando o

\footnotetext{
13 Silva, Como enfrentar a síndrome da folha em branco, 5.

14 Silva, Como enfrentar a síndrome da folha em branco, 5.
} 
imediatismo da opinião e do senso comum, buscando expedientes de universalização e generalidade». ${ }^{15}$

Estas questões científicas, de um campo majoritário, estabeleceram certo controle e um conjunto de regras de enunciação que contribuíram para que a linguagem aparecesse de forma neutra e impessoal na produção acadêmica. No entanto, não pretendemos adentrar nos discursos do que seria científico ou não, do que é validado como conhecimento, mas propormos um olhar sobre uma escrita que perpassa esse contexto e trata do subjetivo, de uma abertura aos controles de verdades e de linguagens. Falaremos de uma escrita que não busca persuadir e convencer o leitor, mas propõe uma negociação, uma produção de sentidos, uma relativização e abertura ao acolher as experiências dos sujeitos e suas diferentes formas de racionalidades. Desse modo, a escrita ensaística propõe que a produção do conhecimento se dê por diferentes caminhos, por diferentes formas de escrita, mas que são relevantes e potentes para o campo da pesquisa e da educação.

Dessa forma, a escrita acadêmica contempla uma infinidade de combinações: podemos escrever ensaios, relatos, comunicações, análises de discurso, etc. Há espaço para muitas formas de escrita, o que poderia também incluir uma escrita que se dá por um processo mais singular, que envolve outros elementos mobilizadores de uma pesquisa e da produção do conhecimento no campo educativo. Os apavoramentos, já mencionados, também estão vinculados às incertezas desta escrita pluralista e da necessidade que os acadêmicos sentem em produzir uma escrita vinculada a um certo padrão, como se a mesma fosse composta de uma única forma. Dessa ordem, há um padrão empírico de produzir conhecimento, certa normatização, isto é, há uma escrita que é passível de ser mensurada e de ser qualificada como certa ou errada, e estas acabam por causar tensões, pela busca em acertar, muitas vezes, bloqueando outras escritas, tais como uma escrita em primeira pessoa ou uma escrita ensaística.

\section{AS EXPERIÊNCIAS COM O ESCREVER «ENTRE» TRAVESSIAS E PERCURSOS}

Ao problematizarmos a escrita acadêmica nos encontramos nos meandros do domínio da palavra, dos seus significados, suas verdades,

\footnotetext{
15 Pereira, "A escrita acadêmica», 4.
} 
seus discursos, e as possíveis negociações que realizamos ao escrever. Podemos nos relacionar com a palavra, e também com a pesquisa, de inúmeras maneiras. Neste artigo, procuramos nos aproximar da escrita acadêmica pelo viés da experiência, do ensaio, para pensarmos nos percursos e travessias deste processo.

Desse modo, Larrosa ${ }^{16}$ propõe que nos aproximemos da escrita através da experiência, daquilo que nos é singular, a partir de ler e escrever sobre o que nos passa, nos acontece, não no sentido de construir informações ou opiniões com a pesquisa, mas sim que a experiência seja produzida com o leitor, daquilo que pode lhe acontecer ao ler. Esta experiência se alia a um território de passagem, do ler ao escrever, como uma travessia, que produz outros sentidos às palavras lidas, relacionando outras experiências ao que lemos, a tudo que pode acontecer neste percurso, suas alegrias, seus apavoramentos, produzindo sentidos e escritas outras.

Assim, selecionamos o que lemos, da mesma forma como selecionamos os orientadores para as pretendidas pesquisas. A definição de um escopo teórico, de autores que posam dialogar com o tema que se deseja investigar, é importante nesse percurso. A leitura se torna, além de prazerosa, potente como experiência que pode vir a irromper em uma escrita, tornando a leitura a travessia de quem produz sentidos a partir da palavra. A posterior seleção de fragmentos do texto, através de fichas de leituras, ou mesmo apontamentos no livro (assim como por outros métodos) podem movimentar a passagem do ler para o escrever, mesmo que por vezes esse trânsito possa ser conturbado.

No decorrer desta experiência de escrita, acompanhamos alguns apavoramentos e inquietações dos estudantes. A dificuldade de iniciar a escrita, como já mencionado, foi recorrente na elaboração dos projetos de ensino e pesquisa e nos trabalhos de conclusão de curso. Principalmente pelo entrelaçamento inevitável da leitura à escrita, como nos diz Oliveira: «a escrita é irmã gêmea da leitura, nascem juntas, do mesmo parto, embora em tempos diferentes. Pode haver leitura sem escrita, mas dificilmente haverá escrita sem leitura». ${ }^{17}$

\footnotetext{
16 Jorge Larrosa, Tremores: Escritos sobre experiência (Belo Horizonte: Autentica Editora, 2016), 25.

17 Marilda Oliveira de Oliveira, "Como produzir clarões nas pesquisas em educação?», Revista de Educação Pública 24, no. 56 (2015): 445.
} 
A importância da leitura também é abordada por Barthes, ${ }^{18}$ ao propor que podemos ler inúmeros objetos, como «textos, imagens, cidades, rostos, gestos, cenas, etc», e é ao ler que o sujeito poderá subverter a ordem das palavras, seus significados, ao voltar-se para a escrita, "a leitura é condutora do desejo de escrever». ${ }^{19} \mathrm{Um}$ desejo de escrita que não se faz na repetição da leitura, mas se dá na provocação com a leitura, assim uma está implícita na outra.

Nessa perspectiva a leitura é verdadeiramente uma produção: não mais de imagens interiores, de projeções, de fantasias, mas, literalmente, de trabalho: o produto (consumido) é devolvido em produção, em promessa, em desejo de produção, e a cadeia dos desejos começa a desenrolar-se, cada leitura valendo pela escritura que ela gera, até o infinito. ${ }^{20}$

A leitura é também produção, produção do desejo de escrever, de uma escrita que se desenlaça dos autores, que propõe a morte do autor, como nos aponta Barthes. ${ }^{21}$ Que se faz ao libertarmos a palavra, segundo Larrosa, ${ }^{22}$ no qual o papel do autor perde sua importância significativa, para que o leitor possa assumir seu papel de produtor, por um processo de invenção com a escrita. Para que a produção da escrita aconteça, é preciso leitura, um movimento que algumas vezes acarreta em apavoramentos com relação à escrita acadêmica.

Nesse processo de pensar sobre a escrita acadêmica, os estudantes se propõem a realizar esse movimento entre a leitura e a escrita. Assumimos que durante esse processo podem haver apavoramentos também da ordem do excesso. Excesso de leituras, autores e conceitos, que podem enrijecer a escrita, pelo deslumbramento com os textos. Ou até mesmo dificultar o processo de escrita pelo excesso de livros, artigos e capítulos que nos interessam. O processo de escolha do que vamos ler, do que pode movimentar a escrita, os autores e livros que vamos inserir para

\footnotetext{
18 Roland Barthes, O Rumor da Língua, (São Paulo: Martins Fontes, 2004, $2^{\mathrm{a}}$ ed.), 32.

19 Barthes, O Rumor da Língua, 39.

20 Barthes, $O$ Rumor da Língua, 40.

21 Barthes, O Rumor da Língua, 57.

22 Jorge Larrosa, Nietzsche \& a Educação (Belo Horizonte: Autêntica, 2009, 3ª ed.), 105.
} 
potencializar a produção de outros sentidos, é um importante elemento da pesquisa a ser abordado com atenção.

A seleção de textos em demasia pode causar o apavoramento pela quantidade exacerbada e irreal, assim como pode haver a percepção distorcida de que se escrevermos em grande quantidade haverá um adensamento teórico no texto. Para que a leitura possa contribuir com a pesquisa, exclui-se alguns autores em prol do que potencializa a escrita, assim como podemos excluir conceitos e páginas excedentes que tornam o texto repetitivo com relação ao que lemos e pouco enredado à criação, pela produção do leitor/a/escritor/a.

Nos aproximamos de uma escrita que é produzida por um leitor, o que Barthes nomeou como um processo de texto-leitura, que não se pauta no simples entendimento do que o autor quis dizer, mas no que o leitor produz com estas palavras. Barthes nos questiona, «nunca lhe aconteceu, ao ler um livro, interromper com frequência a leitura, não por desinteresse, mas, ao contrário, por afluxo de ideias, excitações, associações? Numa palavra, nunca lhe aconteceu ler levantando a cabeça?».23 Nesta experiência de leitura, muitas vezes, levantamos a cabeça e produzimos um outro texto mentalmente, neste processo estamos produzindo também outros sentidos para o texto lido.

Assim, ler é abrir o texto a todas as possíveis experiências que podemos ter com ele. Segundo Barthes, ${ }^{24} \mathrm{o}$ ato de ler é também um trabalho do próprio corpo, que é atravessado pelos signos do texto e gera no leitor diferentes posturas e composições, para então, haver a produção de sentidos outros com as suas frases, para além do próprio texto.

Deste modo, articulamos a produção da escrita para que crie relações entre os autores, produzindo outros textos e sentidos com os signos e palavras ali encontradas, articulando seus argumentos e suas falas no decorrer do texto. A escrita acadêmica perpassa a interlocução entre diferentes autores e a produção de sentido que é singular a cada vez que fazemos crescer palavras em nossos textos.

\footnotetext{
${ }^{23}$ Barthes, O Rumor da Língua, 26.

${ }^{24}$ Barthes, O Rumor da Lingua, 29.
} 
O ensaio é uma possibilidade de escrita através da experimentação, como processo de invenção, escrita-ensaio. Para a escrita acadêmica de professores/as em formação em um curso de licenciatura em artes visuais, propomos que a escrita possa se articular com a imagem, em um diálogo entre o texto e imagem. Esse entrelaçamento apresenta a imagem operando com o texto, no sentido de produzir outros sentidos, além dos já ditos pelas palavras, mas que estejam atravessando o texto.

Operar a imagem em meio ao texto, não é uma tarefa fácil, mas potencializa a pesquisa que se faz entre a arte e a educação, assim como para diferentes cursos de formação. Podemos nos questionar sempre que incluirmos uma imagem junto à escrita acadêmica: se ela não estiver ali, fará falta? Se a resposta for afirmativa a imagem potencializa o diálogo com o texto, e pode ser pertinente neste contexto. Assim como se a imagem estiver deslocada dos questionamentos apresentados pelo texto, seu posicionamento não será potente para o processo de escrita. Da mesma forma, quem escreve no texto a descrição da imagem, ou apresenta a imagem como ilustração do texto, pode não potencializar seu uso.

Para isso propomos que, assim como realizamos a seleção dos autores, possamos também selecionar as imagens que comporão o texto. A partir de obras de arte que dialoguem com o tema investigado, de diferentes artistas, assim como imagens cotidianas, produzidas ou não pelo pesquisador/pesquisadora, que possam potencializar o processo de escrever. Cada pesquisador/pesquisadora poderá movimentar esse diálogo entre imagem e escrita a partir de seu olhar atento e problematizador.

A produção de uma escrita que se insira em uma pesquisa, seja para os projetos de ensino e pesquisa ou para os trabalhos finais de graduação, a partir de uma abordagem pela experiência, pode acolher a aliança entre as palavras e as imagens, de modo a serem articuladas para além da simples representação ou ilustração do que é lido. A imagem que adentra ou perpassa as produções artísticas de cada estudante, assim como a elaboração de diários de pesquisa e a recolha de imagens do cotidiano, podem movimentar a escrita, compondo uma operação de diálogo entre a imagem e a escrita. 
Pela experiência, pode ser que algo nos lança a pensar, a escrever, a produzir sentidos, entre a própria experiência e a travessia de quem escreve, entre leituras que se atravessam nesse processo. Escrever, pensar e aprender podem produzir estranhamentos, que movimentam as certezas e as verdades que tendem a significar as palavras e o mundo. Pela experiência irrompemos esse estranhamento com o outro, abrindo possibilidades de negociações e travessias entre a leitura e a escrita.

Para Deleuze, ${ }^{25}$ o pensamento não nos é instintivo, algo estranho necessita forçar o pensar, como uma provocação diante do encontro, o acontecimento impele o movimento do pensamento. Como salienta Deleuze, "o que nos força a pensar é o signo»;26 o signo é o movimento do pensamento, que por diferentes conjunturas pode levar o pensamento a diferentes caminhos e composições.

Nesse sentido, algumas ações podem potencializar esse processo da escrita acadêmica. Articular a experiência da leitura ao processo de escrita é pensar também o que «nos passa, nos acontece, o que nos toca ${ }^{27}$ nessa experimentação que é uma produção singular diante dos encontros que temos. Relacionar a experiência ao que nos afeta, tanto ao escritor/a como ao leitor/a, pode ser potente para a produção de uma escrita, ao estarmos dispostos a esta travessia da experiência, do acontecimento, do encontro com o outro. Potencializar uma leitura que mova as palavras, e que nos lance na vontade de escrever, rasurar, emaranhar.

Ribetto $^{28}$ partilha dessa proposição da experiência como algo que nos passa, desse «meio», desse território de passagem, que está em movimento constante e deixa rastros. A autora questiona, «Como escrever na passagem? [...] Escrever passando? Passar e escrever». ${ }^{29}$

\footnotetext{
${ }_{25}$ Gilles Deleuze, Proust e os signos (Rio de Janeiro: Forense Universitária, 2006, 2a ed.), 91.

26 Deleuze, Proust e os signos, 91.

27 Larrosa, Tremores, 18.

28 Anelice Ribetto, "Experiência, experimentações e restos na escrita acadêmica», en Uma escrita acadêmica outra: ensaios, experiências e invenções, orgs. Cristiana Callai e Anelice Ribetto (Rio de Janeiro: Lamparina, 2016), 58-67.

${ }^{29}$ Ribetto, "Experiência, experimentações e restos na escrita acadêmica», 60.
} 
Apostar no mínimo é uma escolha pelo abandono das narrações e descrições de grandes fatos heroicos que habitualmente nos contam os grandes projetos político-pedagógicos, as inovadoras reformas educacionais, as heroicas práticas de superprofessores engajados etc; pois essa é uma narração que opera na produção de uma língua que não acolhe o gaguejar das línguas dos sujeitos que praticam a educação cotidianamente e a praticam inscrevendo nos seus corpos a experiência de replicação, mas também de fugas dos modelos dados a priori. ${ }^{30}$

Essa escrita tramada na experiência, se faz por uma escrita menor, sem pretensões de encontrar respostas definitivas e homogeneizadoras para as pesquisas ou para a educação, mas que possa afirmar a potência desses fragmentos, das sobras, para pensar a educação e a própria escrita, pelas «outras formas de produzir texto na academia». ${ }^{31}$

Ao iniciar uma pesquisa e uma escrita, muitas vezes ficamos tomados pelos apavoramentos da página em branco, como citado anteriormente a partir de Silva. ${ }^{32}$ Muito se questiona por onde podemos iniciar uma escrita. Ao que nos parece a escrita se apresenta com início, meio e fim, somente quando finalizada. Porém escrever corresponde a estar em «meio». Em «meio» ao que nos afeta, em «meio» a uma leitura, em «meio» a um turbilhão de outros espaços que se atravessam e dialogam entre uma pesquisa, o seu processo de escrita e a vida. A escrita se inicia no "meio». Talvez escrever possa ser primeiramente lançar palavras na página em branco, para enfim sair do apavoramento inicial. Escrever, apenas. Talvez não se articulem nesse momento os autores que foram convocados para a leitura, mas a escrita mesmo que pessoal, fragmentária de um diário pessoal, pode ser potente, como um resto que movimenta a escrita.

Assim, propomos pensar uma escrita que não estabeleça a criação de verdades absolutas, de doutrinas generalizadoras, mas sim um movimento de estar à espreita, como coloca Deleuze ${ }^{33}$ daquilo que movimenta

\footnotetext{
30 Ribetto, «Experiência, experimentações e restos na escrita acadêmica», 65.

31 Ribetto, "Experiência, experimentações e restos na escrita acadêmica», 58.

32 Silva, Como enfrentar a síndrome da folha em branco, 4.

33 Gilles Deleuze, O Abecedário de Gilles Deleuze. Realização de Pierre-André Boutang, produzido pelas Éditions Montparnasse, Paris. No Brasil, foi divulgado pela TV Escola, Ministério da Educação.
} 
o pensamento, no que tange à educação e à vida. Este processo se inicia como um convite a pensar a leitura e a escrita através desta perspectiva, articulando a produção do conhecimento à vida.

Portanto, a estruturação dos projetos de ensino e pesquisa e dos trabalhos de conclusão de curso, foram pensados com o rigor acadêmico, de uma escrita que aborda o tema, o problema, os objetivos, o marco teórico, o cronograma e as referências. Mas, igualmente, permitiu a inserção de muitos outros elementos, através de atravessamentos constantes. Entre a escrita e a imagem; seu caráter provisório, ao ser repensado a cada semestre; a cada novo autor que mobiliza a escrita, entre o seu recomeço pelo "meio», através de uma escrita que se faz, muitas vezes, por fragmentos. A elaboração da escrita baseou-se na relação entre a provisoriedade e a infinidade de temas, perspectivas, caminhos, para a escrita de cada estudante. Assim, o que permeou a escrita se delineou em um território poroso e mutável, no qual o que age é o pensamento e a invenção, e em cada projeto se desenvolveu todo um pensamento-palavra, como nos diz Larrosa. ${ }^{34}$

Cristian Mossi ${ }^{35}$ nos propõe pensarmos na elaboração de projetos e nas docências como lugares de criação e experimentação:

[...] como pode uma docência em artes visuais, dessa forma, se beneficiar dessas noções na criação de projetos de ensino? Como produzir projetos de ensino e fazer, na escrita desses projetos, aparecer uma docência como lugar de criação? Que leituras mobilizam nosso pensar em direção a criar? Que visualidades compõem paisagens inventivas para nossas docências, para os projetos que criamos?. ${ }^{36}$

Nesse sentido, a elaboração dos projetos de ensino e pesquisa e dos trabalhos de conclusão de curso pode ser pensada a partir de «infinitas

Tradução e Legendas: Raccord [com modificações]. A série de entrevistas, feita por Claire Parnet, foi filmada nos anos 1988-1989.

34 Larrosa, Tremores, 16.

35 Cristian Poletti Mossi, «Notas disparadoras para a criação de projetos de ensino em educação das artes visuais», Cadernos de Pesquisa: Pensamento Educacional 11, no. 29 (2016): 133-150.

${ }^{36}$ Mossi, "Notas disparadoras para a criação de projetos de ensino em educação das artes visuais», 3. 
possibilidades de invenção e articulação de caminhos, práticas, metodologias, territórios, processos, materialidades existentes e inexistentes ${ }^{37}$ podendo ser repensada, alterada e reformulada. Esta composição diversa da escrita, possibilita reorganizar os territórios educativos e os territórios da pesquisa, por conseguinte, também a educação que perpassa a formação de professores/as, possibilitando tanto uma escrita quanto uma aula que apresentem a invenção e a experimentação como percursos possíveis para as diversas docências.

\section{O ENSAIO COMO POSSIBILIDADE PARA A ESCRITA ACADÊMICA}

Ao articular a escrita dos projetos de ensino e pesquisa e dos trabalhos de conclusão de curso a um processo de invenção, nos aproximamos do que Larrosa ${ }^{38}$ expõe sobre o ensaio como possibilidade de escrita acadêmica. $\mathrm{O}$ autor pontua-o como um gênero impuro, por confundir e/ou misturar ciência, conhecimento, objetividade e racionalidade, à arte, imaginação, subjetividade e irracionalidade. O ensaio borra tais fronteiras, põe em questionamento esses mecanismos de divisão e exclusão. Enreda as diferenças entre ciência, arte e filosofia, por dar liberdade temática e formal a quem escreve, o que pode incomodar os campos que regularizam os saberes de modo organizado e compartimentalizado.

«Tudo o que não se enquadra em um padrão de alguns paradigmas reconhecidos, que não se ajusta às classificações em uso, que não se sabe o que é e para que serve, é suprimido e ignorado pelo aparente elogio de "sugestivo" ».39 A impureza e a liberdade do ensaio incomodam os administradores da pureza, os burocratas da compartimentalização universitária.

Além de pôr em dúvida os modos cartesianos de pensamento, de saberes, de escritas, aqui já mencionados, Larrosa propõe o ensaio como uma escrita que acolhe a experiência como produção de conhecimento. Nesse sentido, expõe algumas percepções de sua perspectiva para o modo de escrita do ensaio. O ensaísta tem a liberdade de escolha

\footnotetext{
${ }^{37}$ Mossi, «Notas disparadoras para a criação de projetos de ensino em educação das artes visuais», 6.

${ }^{38}$ Larrosa, "O ensaio e a escrita acadêmica», 22.

${ }^{39}$ Larrosa, "O ensaio e a escrita acadêmica», 22.
} 
perante os temas de pesquisa e a organização formal da mesma; é um leitor que escreve, que problematiza a leitura e a escrita; que se demora na força do texto e nas paixões dali produzidas; tem como possibilidade expressar-se livremente; é um transeunte, divagador, explorador; escreve de forma provisória em seu contexto singular; tem o método como problema e se adapta ao percurso; começa e termina pelo «meio», no «entre» dos encontros; desdobra os conceitos na experiência, tece palavras lançando-as ao vazio, quando nos despimos das verdades, normas e representações que tendem a organizar o pensamento, e produzimos outros sentidos além dos já sabidos.

Para a escrita acadêmica, o ensaio se torna uma possibilidade potente para articular a pesquisa à experiência, a partir da escolha de cada estudante, dos temas que os mobilizam a pesquisar e da liberdade de recolha de suas materialidades, contidas muitas vezes em seus percursos formativos e suas andanças enquanto professores/as e pesquisadores/as. Desse modo, a escrita mais incluí, desde autores a própria organização da escrita e a formatação de seus textos, que excluí; apresenta mais travessias do que pontos de chegada.

O espaço acadêmico tornou a leitura obrigatória, ao mesmo tempo, os leitores juízes do que leem, pois cobra-se um posicionamento dos mesmos, se é a favor ou contra, se está de acordo ou desacordo. Esqueceu-se da lentidão da leitura, a delicadeza das palavras, de tratar o texto como uma força que nos leva para além de nós mesmos, além do que o texto diz, do que o texto pensa, do que o texto sabe. Esqueceu-se, ou melhor, nunca se aprendeu a arte da leitura. «Ler devagar, com profundidade, com intensidade, portas abertas e olhos e dedos delicados». ${ }^{40}$

O ensaísta não parte do nada, mas de algo preexistente, mais especificamente de suas paixões, de seu amor e ódio pelo que se lê, que não diz respeito a estar de acordo ou desacordo, não é verificar ou refutar, não tem a ver com verdade ou erro. Quando o ensaísta lê, «ri ou se enfada, se emociona ou pensa em outra coisa que a leitura lhe evoca. E seu ensaio, a sua escrita ensaística, não apaga o riso nem o enfado, nem suas

\footnotetext{
40 Friedrich Nietzsche, Aurora (São Paulo: Companhia das Letras, 2004), 14.
} 
emoções e evocações» ${ }^{41}$. Para tanto, a escrita acadêmica, com os seus pressupostos, "é alérgica ao riso, à subjetividade e à paixão».42

Assim, quando nos propomos a compartilhar nossas experiências com a orientação de projetos de ensino e pesquisa e trabalhos de conclusão de curso, pensamos as possibilidades que delas ocorreram por meio do ensaio, sem pretensão de totalidade, de sistemáticas. São escritas fragmentadas, parciais, que selecionam «um corpus, uma citação, um acontecimento, uma paisagem, uma sensação", ${ }^{43}$ algo ínfimo, algo que lhe pareça expressivo, e que possa ser potencializado enquanto escrita.

Para tanto, o ensaio instala nesses exercícios de escrita uma dúvida sobre o método, isto é, transpõe o método para um problema, e, portanto, serão pesquisas e projetos metodologicamente inventivos. Para Larrosa, ${ }^{44}$ o método quando se fossiliza, se torna uma figura linear, retilínea, que não acolhe o sinuoso, os acidentes do caminho, os entraves do percurso. Temos proposto pensar sob vias do ensaio, visto que o que nos interessa são esses traços singulares, tortuosos, desviantes, que cada acadêmico atribuí à sua escrita, às suas divagações, extravagâncias e encontros que estão a ter com a docência, com a formação docente inicial. Preocupamo-nos com métodos que traçam determinados caminhos, de modo prévio, que por vezes enrijecem a própria pesquisa, e procuram controlar onde ela vai chegar.

Compartilhamos, assim, que os projetos de ensino e pesquisa e os trabalhos de conclusão de curso da licenciatura em artes visuais têm abordado o ensaio como modo de escrever, como reconhecimento de uma escrita acadêmica, visto que temos orientado pesquisas por este viés da experimentação entre a escrita-ensaio e suas possibilidades para a produção do conhecimento do cenário acadêmico. Apostamos em uma produção escrita enredada por movimentos orgânicos, não tanto por definições de conceitos, mas desdobrando-os e tecendo palavras, levando-as ao limite do dizível, deixando-as à deriva. Assim, a pesquisa se faz nas descontinuidades; afinal, a vida é mesmo descontínua.

\footnotetext{
41 Larrosa, "O ensaio e a escrita acadêmica», 25.

42 Larrosa, "O ensaio e a escrita acadêmica», 25.

43 Larrosa, "O ensaio e a escrita acadêmica», 26.

${ }^{44}$ Larrosa, "O ensaio e a escrita acadêmica», 26-27.
} 
Neste sentido, nos questionamos, qual seria a relevância da orientação destas escritas? Oliveira nos apresenta uma possibilidade, ao questionar-se, "como produzir clarões em meio às nossas aulas, aos nossos textos, às orientações de dissertações e teses?».45 Estes clarões foram pensados por Deleuze como a produção de tensões, fricções, que articulados por Oliveira nos levam a pensar nas tensões e fricções de planos de aula e das pesquisas na educação. Assim, esta produção diz respeito à criação, quando, em meio aos projetos de ensino e pesquisa e aos trabalhos de conclusão de curso, a escrita é atravessada pela invenção.

Desse modo, o papel de quem faz parte da orientação dessas escritas pode ser visto pela ordem das provocações, problematizações, questionamentos, no que diz respeito a todo discurso que perpassa a escrita, e tudo que desse território pode ser pensado. Segundo Oliveira, «é este o papel do tensor. Armar tensores em todo o texto e extrair daí durações e diferentes intensidades». ${ }^{46}$ criar tensão entre a escrita, as imagens, os autores e sua produção reorganizada pela escritura, papel tanto de quem escreve, de permitir brechas para o leitor friccionar o texto, assim como de quem orienta, de possibilitar a tensão entre palavras e conceitos, que possam ser atravessadas pela invenção na escrita.

\section{CONSIDERAÇÕES FINAIS}

Ao acolhermos uma escrita ensaística que aproxima a experiência da pesquisa, o ato de escrever passa a acontecer quando o pensamento é movido a sair de um estado inerte, trata-se de uma perda de controle do que irá nos afetar nessa travessia. Como já nos disse Deleuze ${ }^{47}$ forçar o pensamento a acolher o que nos impele ao desassossego, à impaciência, é uma tarefa difícil, mas potente para esse processo em que se encontram os professores/as em formação, ou a quem deseja escrever. Se a escrita não acontece de pronto, a ansiedade se instala entre as letras, e as palavras fogem do pensamento. Assim, percebemos que a escrita acadêmica, muitas vezes, gera apavoramentos.

\footnotetext{
45 Oliveira, «Como produzir clarões nas pesquisas em educação?», 447.

46 Oliveira, «Como produzir clarões nas pesquisas em educação?», 453.

47 Deleuze, Proust e os signos, 91.
} 
Segundo Oliveira é preciso «esperar, insistir, uma e outra vez, muitas vezes, permanecer no meio do perigo da escrita, da solidão, do desespero» ${ }^{48}$ : a escritura necessita de muitos elementos para irromper na folha e na ponta do lápis. Portanto, seria importante para esse processo de escrita, manter a calma, a paciência, dar-se tempo, visto que, a escrita necessita de espaço e escuta para criarmos outros sentidos ao que vemos e experienciamos.

Podemos escrever de forma fragmentária, para poder fazer brotar o texto quando paralisados pelos apavoramentos da escrita. Podemos organizar a escrita a partir de nossos autores, pois escrever e ler são processos conjuntos, conforme afirma Barthes. ${ }^{49}$ Ao ler produzimos outros textos, que articulados pela criação e pela interlocução entre autores, podem mobilizar a produção de uma pesquisa.

A escrita também necessita de um processo de escolha, que irá excluir os excessos: de autores, de conceitos ou de páginas; que poderá articular a imagem enquanto potência para o texto; e acolher a variação de temáticas, métodos, formatos e diagramações. O ensaio pode ser potente para viabilizar a escrita acadêmica a partir destes elementos, articulando a pesquisa à experiência.

Larrosa nos fala da experiência, mas aqui nos aproximamos destas palavras para pensarmos o processo de escrita, que muitas vezes «requer um gesto de interrupção, um gesto que é quase impossível nos tempos que correm [...] cultivar a atenção e a delicadeza, abrir os olhos e os ouvidos».50 Escrever requer leitura, atenção ao que nos mobiliza a produzir textos que aliem a invenção à pesquisa, assim como a outros modos de produzir conhecimento nos espaços acadêmicos.

Portanto, esta escrita conjuga-se por meio de alianças e invenções com as palavras, na travessia com a arte e a literatura, que possibilita a abertura de percursos diversos para aqueles que desejam produzir textos. A escrita-ensaio ou alguns de seus desvios, podem se apresentar como um viés tanto para pesquisadores/pesquisadoras da área da

\footnotetext{
48 Oliveira, "Como produzir clarões nas pesquisas em educação?», 446.

49 Barthes, $O$ rumor da língua, 28-29.

${ }^{50}$ Larrosa, «O ensaio e a escrita acadêmica», 25.
} 
educação das artes visuais, quanto para todos e todas aqueles/aquelas que aceitam o convite de escrever e pesquisar acolhendo variações neste processo.

Nesse contexto, a escrita nos propõe a produção de outros sentidos, para além dos já lidos, a fim de compor uma operação diferente com as palavras e os conceitos. Essa é uma das maiores dificuldades nesse processo de escrita, colocarmo-nos em um ritmo singular, de escutar, olhar e escrever sobre o que nos passa e acontece.

Escrevemos sob modos de endereçamentos para possíveis leitores, mas também para nós mesmos. Nesse sentido, temos orientado que o contributo de uma pesquisa no campo da educação das artes visuais não necessita propor uma transformação nos espaços da pesquisa, ou nos colaboradores, mas que ela possa produzir algo no pesquisador/pesquisadora, produzir sentidos para ele/ela. Propomos que os espaços acadêmicos possam acolher outras formas de escrita que se organizem de modos diferentes, seja em relação ao seu formato ou quanto ao uso das imagens como tensionadoras do texto, produzindo conhecimento e problematizando o campo da pesquisa e da educação.

\section{Nota sobre as autoras}

Carin Cristina Dahmer. Doutoranda no Programa de Pós-Graduação em Educação, Linha de Pesquisa Educação e Artes, na Universidade Federal de Santa Maria (UFSM/RS); Mestra em Educação pela mesma instituição; É Licenciada em Artes Visuais e possui Bacharelado/Licenciatura em História pela mesma instituição. Desenvolve estudos e pesquisas nas seguintes áreas: educação e arte, história da arte e filosofias da diferença.

Angélica Neuscharank. Doutora (2019) e Mestra (2015) em Educação pelo Programa de Pós-graduação em Educação (PPGE), na linha de Pesquisa Educação e Artes - LP4, ambos pela Universidade Federal de Santa Maria (UFSM/RS). Pós-graduação - Especialização em Tecnologias da Informação e da Comunicação Aplicadas à Educação (2014) e graduação em Artes Visuais - Licenciatura Plena em Desenho e Plástica (2011), pela mesma instituição. Vem desenvolvendo estudos nas seguintes áreas: arte, educação, docência e filosofias da diferença 
Marilda Oliveira de Oliveira. Doutora em História da Arte e Mestra em Antropologia Social, ambas pela Universidad de Barcelona, Espanha. Licenciada e Bacharel em Artes Visuais pela Universidade Federal de Santa Maria, RS. Professora do Programa de Pós-Graduação em Educação da UFSM, onde orienta trabalhos de mestrado e doutorado na linha de pesquisa 'Educação e Artes'. Editora chefe da Revista Digital do LAV. Coordenadora do GEPAEC - Grupo de Estudos e Pesquisas em Arte, Educação e Cultura.

\section{REFERÊNCIAS}

Barthes, Roland. O Rumor da Língua. 2a ed. São Paulo: Martins Fontes, 2004. Deleuze, Gilles. O Abecedário de Gilles Deleuze. Realização de Pierre-André Boutang, produzido pelas Éditions Montparnasse, Paris. No Brasil, foi divulgado pela TV Escola, Ministério da Educação. Tradução e Legendas: Raccord [com modificações]. A série de entrevistas, feita por Claire Parnet, foi filmada nos anos 1988-1989.

Deleuze, Gilles y Claire Parnet. Diálogos. São Paulo: Editora Escuta, 1998.

Deleuze, Gilles. Proust e os signos. $2^{\mathrm{a}}$ ed. Rio de Janeiro: Forense Universitária, 2006.

Larrosa, Jorge. Nietzsche \& a Educação. 3 ed. Belo Horizonte: Autentica, 2009.

Larrosa, Jorge. Tremores:Escritos sobre experiência. Belo Horizonte: Autentica Editora, 2016.

Larrosa, Jorge. "O ensaio e a escrita acadêmica». In Uma escrita acadêmica outra: ensaios, experiências e invenções, editado por Cristiana Callai e Anelice Ribetto, 17-30. Rio de Janeiro: Lamparina, 2016.

Mossi, Cristian Poletti. «Notas disparadoras para a criação de projetos de ensino em educação das artes visuais». Cadernos de Pesquisa: Pensamento Educacional 11, no. 29 (2016): 133-150.

Nietzsche, Friedrich. Aurora. São Paulo: Companhia das Letras, 2004.

Oliveira, Marilda Oliveira de. "Como produzir clarões nas pesquisas em educação?». Revista de Educação Pública 24, no. 56 (2015): 443-454.

Ribetto, Anelice. «Experiência, experimentações e restos na escrita acadêmica». In Uma escrita acadêmica outra: ensaios, experiências e invenções, editado por Cristiana Callai e Anelice Ribetto, 58-67. Rio de Janeiro: Lamparina, 2016.

Silva, Tomaz Tadeu da. Como enfrentar a síndrome da folha em branco. Argumentação, estilo, composição: Introdução a escrita acadêmica. Programa de Pós-Graduação em Educação. Universidade Federal do Rio Grande do Sul. $\mathrm{S} / \mathrm{d}$. 
Pereira, Marcos Villela. «A escrita acadêmica: do excessivo ao razoável». Revista Brasileira de Educação 18, no.52 (2013): 213-244.

Zourabichvili, François. O vocabulário de Deleuze. Rio de Janeiro: Sinergia Relume Dumará, 2004. 